\title{
Adenosine Receptors and Signaling in the Kidney
}

\author{
W.S. Spielman, L.J. Arend, K.-N. Klotz, and U. Schwabe
}

When adenosine binds to plasma-membrane receptors on a variety of cell types in the kidney, it stimulates functional responses that span the entire spectrum of renal cellular physlology, including alterations in hemodynamics, hormone and neurotransmitter release, and tubular reabsorption (Table 1 ). This array of diverse responses, appears to represent a means by which the kidney and 1 ts constituent cell types can regulate the metabolic demand such that it is maintained at an appropriate level for the prevalling metabolic supply (Figure 1). With the increased recognition of this wide array of renal cellular actions, and the continuing development of relatively specific adenosine receptor agonist and antagonist 1 igands, investigators have undertaken the task of assigning the different renal actions of adenosine to the known adenosine receptor types, by comparison of relative agonist and antagonist potencies. It is apparent from the inspection of a list of the renal actions of adenosine, that not only does adenosine control a variety of functions but it appears to have a "dual-control" over many aspects of renal function mediated by separate receptors. This approach, while providing useful information on the action and the possible receptor subtypes leaves some questions as to the coupling to second messenger systems, and does not provide molecular information of the subcellular events that may be involved.

With the exception of their ability to respond to adenosine and adenosine analogs, nothing as yet has been described that distinguishes adenosine receptors from the wide variety of receptors that modify adenylate cyclase activity and are therefore likely members of a large class of hormone receptors that, like the visual pigment rhodopsin, are coupled to their intracellular effector systems by guanine nucleotide binding proteins. In some systems, however, it has been impossible to correlate physiological responses to adenosine with changes in levels of CAMP, and therefore, it has been proposed that adenosine may be coupled to other signal transduction systems as well. In the kidney, several of the actions of adenosine assoclated with activation of the $A_{1}$ receptor (i.e. vasoconstriction, renin release inhibition, and inhibition of neurotransmitter release) are effects that have been proposed to be mediated by changes in cytosolic calcium (Churchili and Churchill, 1988). We have recently reported in primary cultures of rabbit cortical collecting tubule cells (Arend et al., 1988) and in an established cell derived from RCCT cells (Arend et al., 1989) that in addition to the classical $A_{1}$ and $A_{2}$ receptors coupled to the the inhibition and stimulation of adenylate cyclase (Arend et al., 1987), adenosine stimulates the turnover of inositol phosphates and 
Hemodynamic ( GFR)................

$\begin{array}{ll}\text { vasoconstriction (preglomerular) } & A_{1} \\ \text { vasodilation (postglomerular) } & A_{2}\end{array}$

Hormona $1 /$ Neurotransmitter............. Renin release Inhibition Stimulation

Erythropoietin.................

Inhibition

Stimulation

Adrenergic Transmission

Inhibition (presynaptic)

Tubular ......................

Collecting Tubule

$$
L_{P A}
$$

Thick Ascending Limb

$$
T_{N A}
$$




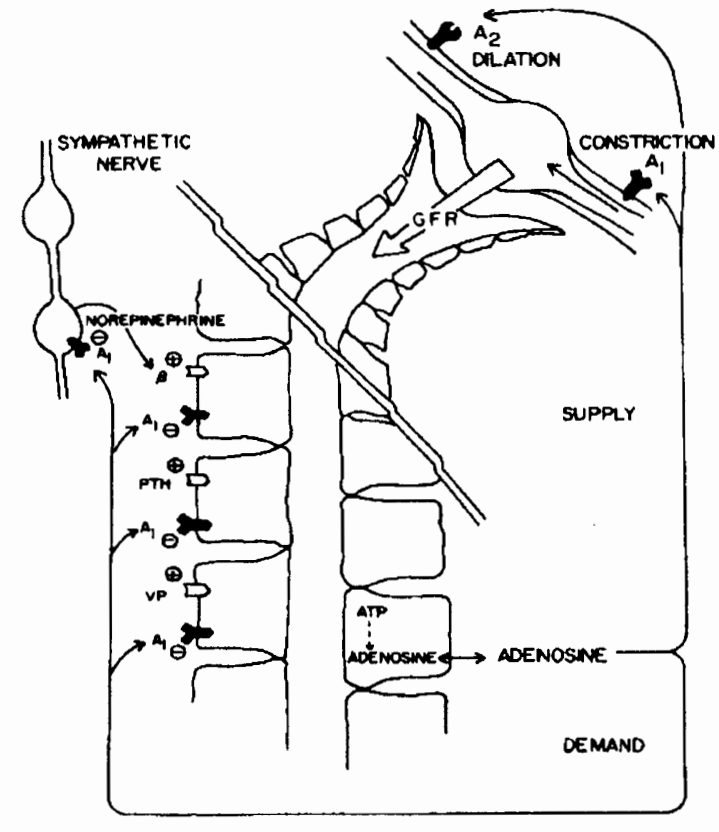

Figure 1. ADENOSINE FEEDBACK HYPOTHESIS FOR THE KIDNEY. Adenosine, presumably produced by transporting epithelium, acts to reduce GFR, via reduction of the glomerular hydrostatic pressure, by its vasoconstrictive action on the afferent arteriole and vasodilatory action on the efferent arteriole, and thereby, regulates the supply of delivered solute to the nephron. The action of adenosine to inhibit hormone-stimulated cyclic AMP in various segments of the nephron, both directly, and indirectly through the inhibition of neurotransmitter release, serves to reduce the metabolic demand of the tubular cells. Together, these hemodynamic and tubular actions of adenosine work to return the metabolic supply and demand ratio toward a level of transport activity appropriate for the oxygen and substrate availability of the tissue.

Radioligand Binding Analysis of Adenosine Al Receptors in 28A Cel1s.

To determine whether or not a single population of $A_{1}$ receptors is coupled to these divergent signaling pathways, we have measured radioligand binding of $\left[{ }^{3} \mathrm{H}\right]$ DPCPX to plasma membranes from rabbit renal medulla and a cell line derived from the rabbit cortical collecting tubule (RCCT-28A). Saturation binding of $\left[{ }^{3} \mathrm{H}\right]$ DPCPX in 28A membranes (Figure 2) analyzed by non-linear curve fitting, gave a one-site model with an apparent $K_{D}$-value of $1.4 \mathrm{nM}$ and $a$ maximum nunber of binding sites (BMAX-value) of $64 \mathrm{fmol} / \mathrm{mg}$ protein. Scatchard analysis of the saturation curve gave a linear plot, indicating the presence of only one homogeneous population of binding sites. The non-specific-binding was 20-308 of the total at the $K_{D}$, and saturation of specific binding was reached with $2 \mathrm{nM}\left[{ }^{3} \mathrm{H}\right]$ DPCPX.

Competition of several agonists for the $\left[{ }^{3} \mathrm{H}\right] \mathrm{DPCPX}$ binding was measured to confirm that $\left[{ }^{3} \mathrm{H}\right]$ DPCPX binds to the $A_{1}$ receptor. Competition of adenosine agonists for $\left[{ }^{3} \mathrm{H}\right] \mathrm{DPCPX}$ binding resulted in biphasic displacement curves (Table 2) indicating the presence of two affinity states for the agonists, with approximately one-half of the binding sites being in the high affinity state and the other half in the low affinity state. The $K_{1}$-values for the various adenosine receptor agonists exhibit the typical pharmacological profile for $A_{1}$ receptors and the marked stereoselectivity for the PIA enantiomers. 


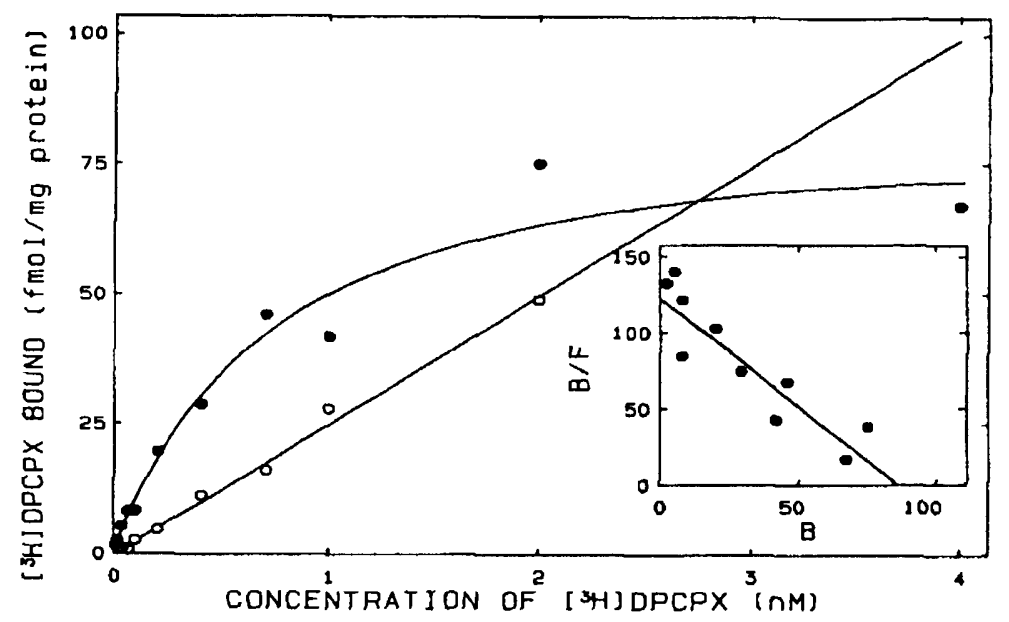

Figure 2. Saturation binding of [3H]DPCPX to RCT-28A cell membranes. Data are given as specific (closed circles) and non-specific binding (open circles). The inset shows the Scatchard plot from the data.

Agonist binding was further characterized by measuring the competition of R-PIA for [ $\left.{ }^{3} \mathrm{H}\right] \mathrm{DPCPX}$ binding in the presence and absence of GTP (100 UM). In the absence of GTP the competition of [ $\left.{ }^{3} \mathrm{H}\right] \mathrm{DPCPX}$ by R-PIA resulted in a biphasic displacement curve with an apparent $K_{D}$-value of $0.5 \mathrm{nM}$ and $B_{\mathrm{MAX}}-\mathrm{value}$ of $16.1 \mathrm{pmol} / \mathrm{mg}$ protein for the high affinity state and a low-affinity $K_{D}$-value of $10.5 \mathrm{nM}$ and $B_{M A X}$-value of 20.2 fmol/mg protein.

When the competition experiment was carried out in the presence of 100 UM GTP, a monophasic curve was obtained, indicating a single affinity state with a $K_{D}$-value of $17.7 \mathrm{nM}$ and a $B_{M A X}$-value of 54.1 fmol/mg protein. Control binding (1008) increased from 36.3 to $54.1 \mathrm{fmol} / \mathrm{mg}$ protein with the addition of 100 uM GTP.

These binding data confirm the previously reported functional data, that cells of the cortical collecting tubule have adenosine $A_{1}$ receptors coupled through GTP-binding proteins. Furthermore, these binding data fail to provide any support for the hypothesis that the inhibition of adenylate cyclase and the stimulation of phospholipase $C$ are coupled to two sub-populations of the $A_{1}$ receptor, although it is recognized that this conclusion may be a function of the inability of currently available ligands to differentiate between the $A_{1}$ receptor subtypes.

Table 2

Pharmacological profile of $\left[{ }^{3} \mathrm{H}\right]$ DPCPX binding to RCCT-28A membranes.

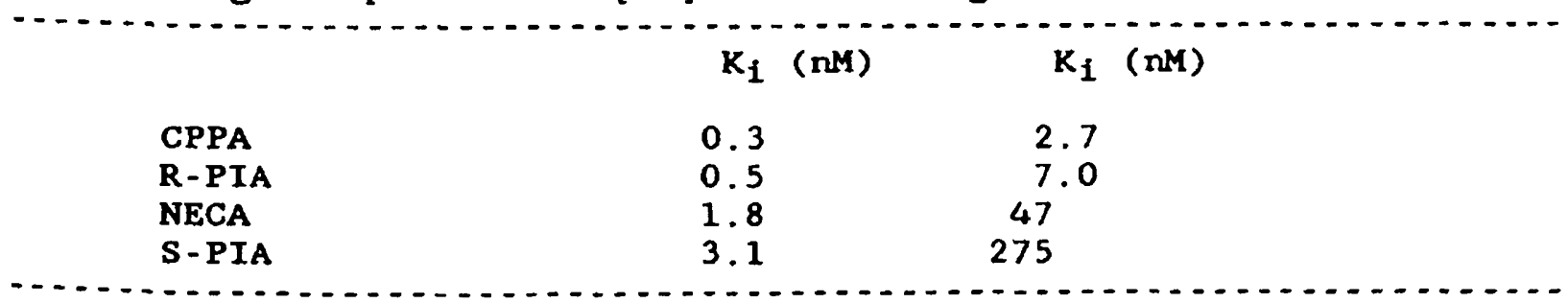


Although the analysis of radioligand binding provided no evidence in support of separate receptor sub-populations of the $A_{1}$ receptor mediating the divergent signaling mechanisms, it remained to be determined if activation of $A_{1}$ receptors was invarlably associated with both inhibition of adenylate cyclase and activation of phospholipase $C$, or alternatively, could the two signaling pathways be regulated separately, providing for more flexibility in control.

Because prior exposure of cells to agonist ligands is often associated with a desensitization of the response to subsequent addition of agonist, we sought to determine if it was possible to selectively desensitize either the $A_{1}$ mediated decrease in adenylate cyclase activity or the $A_{1}$ mediated activation of phospholipase $C$.

To determine if pretreatment of $28 \mathrm{~A}$ cells with $A_{1}$ agonists produced a desensitization of mobilization of intracellular calcium to sebsequent addition of $\mathrm{A}_{1}$ agonist, $28 \mathrm{~A}$ cells were treated for $4 \mathrm{hr}$ with increasing concentrations of CHA, an $A_{1}$ agonist, ranging from $10^{-8}$ to $10^{-4} \mathrm{M}$. During the final hour of exposure to agonist, the cells were loaded with FURA-2, as previously described (Arend et al., 1988), for determination of cytosolic calcium concentration by spectrofluorometry. Cells were then thoroughly washed to remove the extracelluar FURA-2 and $A_{1}$ agonist. Without prior exposure to agonist, 1 uM CHA caused a 408 increase in the cytosolic calcium concentration. With prior exposure to agonist, this action of CHA to cause a stimulation of cytosolic calcium concentration is decreased in a concentration dependent manner.

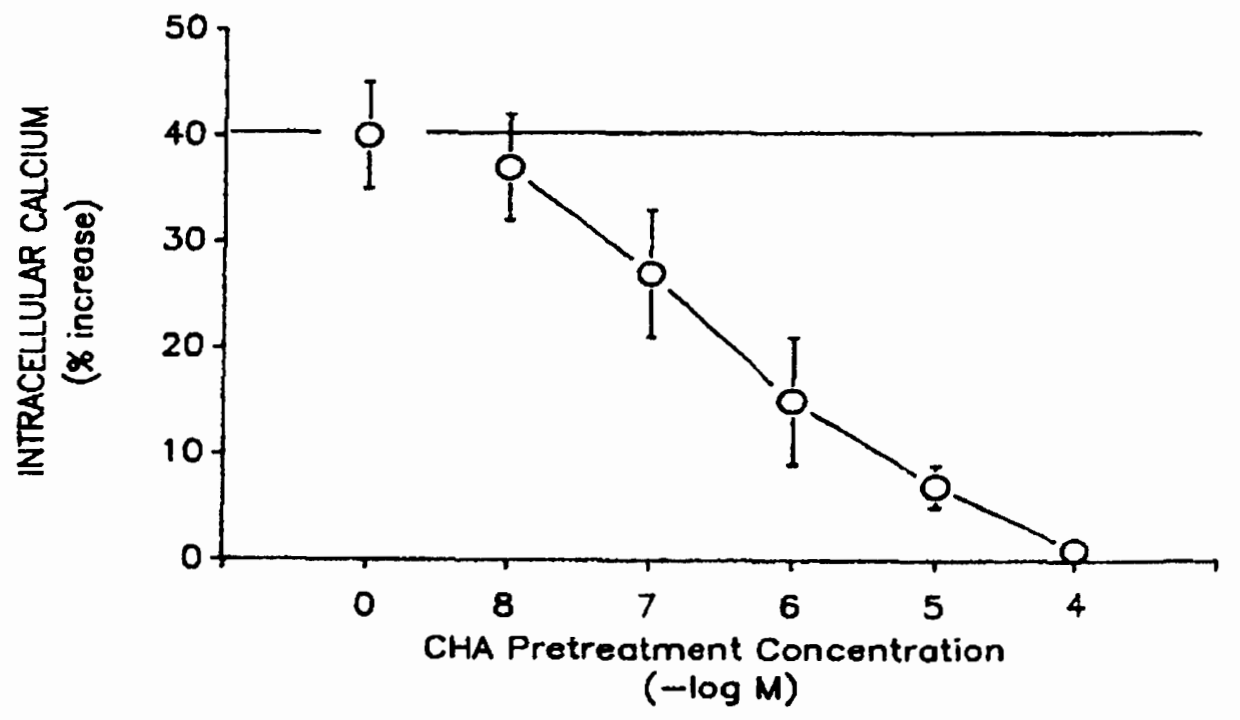

Figure 3. Effect of pretreatment of 28A cells with CHA ( $4 \mathrm{hr}$ ) on CHA induced increase in cytosolic calcium. Values are means \pm SEM of 10 experiments. 


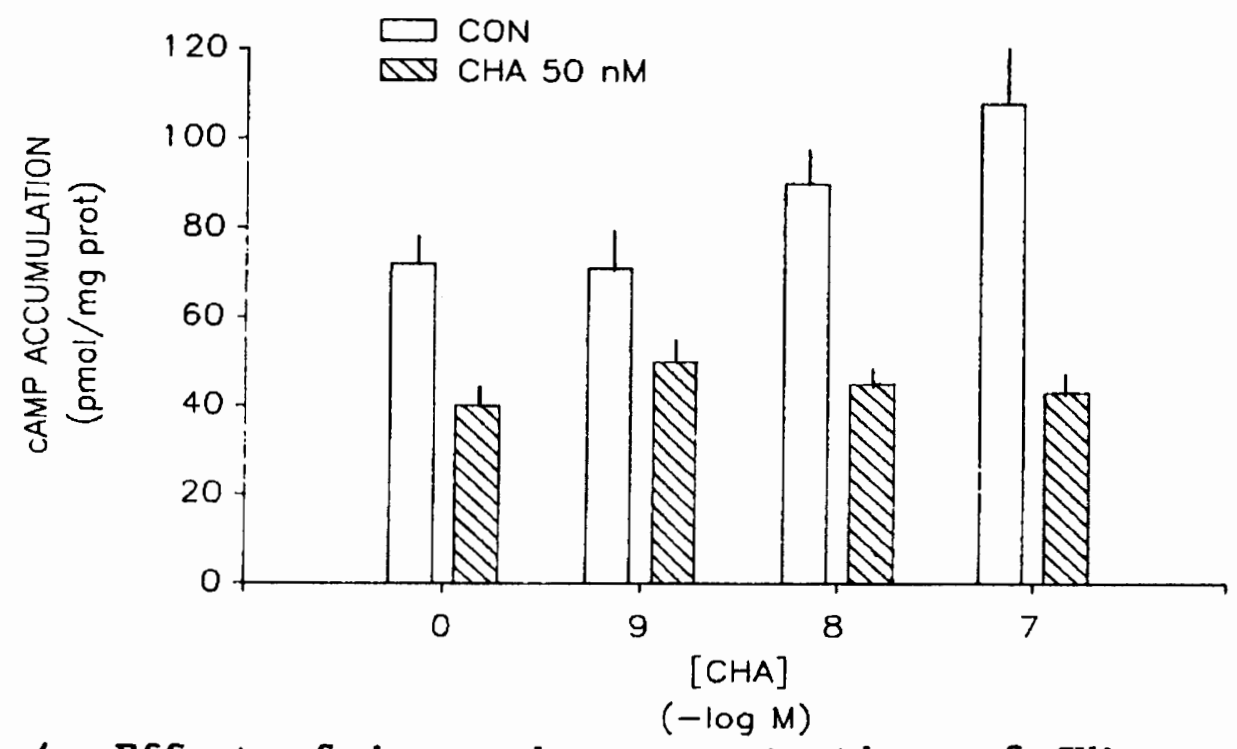

Figure 4. Effect of increasing concentrations of CHA pretreatment (48 hr) on CHA-induced inhibition of cAMP production in 28A cells.

To examine the ability of prior agonist exposure to desensitize the $A_{1}$ Inhibition of adenylate cyclase activity, RCT-28A cells were pretreated for periods of $4,12,24$, and $48 \mathrm{hr}$ with vehicle or CHA at concentrations of 1,10 , and $100 \mathrm{nM}$. The cells were thoroughly washed and then reexposed to $50 \mathrm{nM}$ CHA, the concentration at which we normally see maximal inhibition of cAMP production (Arend et al., 1987) which is approximately 508 (Figure 4). When the cells were pre-exposed to CHA, no alteration in the ability of subsequent addition of $50 \mathrm{nM}$ CHA on cAMP production was observed.

In conclusion, in the absence of evidence of sub-populations of the $A_{1}$ receptor, it appears that activation of a single $A_{1}$ receptor population results in the inhibition of adenylate cyclase and the mobilization of cytosolic calcium. However, the finding that the divergent signaling mechanisms can be differentially regulated raises the possibility of separate control for the activation of phospholipase $C$ and inhibition of adenylate cyclase by adenosine.

\section{References}

Arend, L.J., W.K. Sonnenberg, W. L. Smith, W.S. Spielman. Evidence for $A_{1}$ and $A_{2}$ adenosine receptors in rabbit cortical collecting tubule cells: modulation of hormone stimulated cyclic AMP. J. Clin. Invest. $79: 710-714,1987$.

Arend, L.J., M.A. Burnatowska-Hledin, and W.S. Spielman. Adenosine signal transduction in the rabbit cortical collecting tubule: receptor mediated calcium-mobilization. Am. J. Physiol. 255: F704-F710, 1988.

Arend, L.J., F. Gusovsky, J.H. Daly, J.S. Handler, J.S. Rhim, and W.S. Spielman. Adenosine-sensitive phosphoinositide turnover in a newly established renal cell line. Am. J. Physiol. 256: F1067-F1074, 1989.

Churchill, P.C., and M.C. Churchill. Effects of adenosine on renin secretion. ISI Atlas of Science: Pharmacology. 367-373, 1988. 